\title{
A study of different contraceptive methods: need of the hour during COVID 19 pandemic
}

\section{Monica S. Patokar, Arti S. Shirsath*, Shwetambari R. Shinde, Sameer P. Darawade}

Department of Obstetrics and Gynaecology, Smt Kashibai Navale Medical College and General Hospital, Narhe, Pune, Maharashtra, India

Received: 01 May 2021

Revised: 30 May 2021

Accepted: 31 May 2021

\section{*Correspondence:}

Dr. Arti S. Shirsath,

E-mail: arti.sirsath@gmail.com

Copyright: $@$ the author(s), publisher and licensee Medip Academy. This is an open-access article distributed under the terms of the Creative Commons Attribution Non-Commercial License, which permits unrestricted non-commercial use, distribution, and reproduction in any medium, provided the original work is properly cited.

\section{ABSTRACT}

Background: COVID-19 disease is the pandemic caused by a single-stranded RNA virus that belongs to the coronavirus family known as 2019-nCoV (SARS-Co V). The disease is highly contagious and transmitted mainly by droplets or close contact. In this time of pandemic it is need of the hour to prevent more and more unwanted pregnancies. This study was to evaluate the contraceptive methods of choice which are easily available, cost effective and suitable to most of the patients during this terrible period of pandemic.

Methods: This was a prospective observational study done from April 2020 to December 2020. Women coming to the OPD for contraceptive advice after medical termination of pregnancy and patients desiring postpartum contraception were included in the study. All data were collected from the OPD and IPD of our hospital. Different contraceptive methods available, their costs, hospital visits, complications, failure rate and reason for its discontinuation was analysed. Results: In this study $76.5 \%$ patients (n-459) accepted Inj. DMPA as compared to $10 \%$ used Cu T and $13 \%$ used OC pills as a method of contraception. Inj DMPA is easily available, cost effective, has lesser side effects and need less hospital visits.

Conclusions: DMPA should be made available as a first line method to all those who wishes to opt for reversible method of contraception. This study concludes, during the period of pandemic Inj DMPA was most preferred method of contraception.

Keywords: Contraception, Pandemic, DMPA, COVID

\section{INTRODUCTION}

Globally, approximately $50 \%$ of pregnancies are unintended. ${ }^{1}$ In the poor countries, where access to health care facilities are limited, unwanted pregnancies effects the health of the women, by increasing the risk of unsafe abortions. ${ }^{2}$ COVID-19 is a pandemic disease caused by a single-stranded RNA virus that belongs to the coronavirus family known as 2019-nCoV (SARS-CoV-2). The disease is highly contagious and transmitted mainly by droplets or close contact. What this virus has done to the world is the thing which none of us has ever imagined. On 25 march
2020 India imposed the nationwide lockdown in response to the pandemic of COVID 19. On $14^{\text {th }}$ of April the government has declared abortion as an essential service that needs to be provided during the lock down. But it was very difficult for the people to access the services of safe abortion during this pandemic. ${ }^{3}$

Studies conducted by FRHS (Foundation for Reproductive Health Services) India have found that as a result of the lockdown, 24.55 million couples were unable to access the contraceptive options. There were many victims of gender based violence who were confined to their homes without 
having an escape route. They had no access to emergency or oral contraceptive pills, which during normal situation would be there last resort. Even when the people have access to contraceptives they do not have right information to use it or the money to buy it. FRHS India has expected to have 2.9 million pregnancies as a result of the pandemic even in the best case scenario.

To add to this, there are problems like limited availability of surgical abortion services, barrier to availability of medical abortion drugs at chemists, restricted mobility and lack of transportation services, shutting down of private clinics, and most important amongst them being, increased cost of abortion services in available private sector due to higher input cost owing to infection prevention protocols and social distancing practices. Compulsory covid19 testing is being done for offering surgical method of abortions. Although it is not made mandatory by the Ministry of Health and Family Welfare India but it has resulted in increased cost, making the safe abortion services unavailable to many of the poor people.
Infact FRHS India estimates 1.04 million unsafe abortions this year. Abortion act has always been difficult in India even at the normal times, but now the current problem has made it more difficult by making access almost impossible and the safe abortion techniques unaffordable. So in this hour of crisis it is our responsibility to understand that prevention is better than cure and that is why it is important to find out the best contraceptive that can be offered to the patients with better efficacy, easy availability and cost effective too. Current LARC users should be counselled on the effectiveness of extended use beyond the labelled duration, postponing routine removals. ${ }^{4}$ Training for selfinjection of Sayana Press (DMPA-SC), should be given for women desiring injectable contraception. ${ }^{5}$ Ideal Method of contraception during this period of crisis would be the one which has less side effects, is effective post-delivery or post abortion and most important should reduce the hospital visits of the patients. Table 1 shows the comparison between the three most commonly adviced contraceptive methods.

Table 1: Comparison between OC pills, Inj DMPA, and CuT 380A.

\begin{tabular}{|c|c|c|c|}
\hline Comparison & OC Pills & DMPA & CuT 380 A \\
\hline Failure rate & $0.1 \mathrm{HWY}$ & $0-0.3 \mathrm{HWY}$ & $0.1-2 \mathrm{HWY}$ \\
\hline Compliance & Good & Excellent & Poor \\
\hline Cost & free & $250-300 \mathrm{Rs}$ & free \\
\hline \multirow{5}{*}{ Side effects } & Weight gain & Breakthrough bleeding & Pain \\
\hline & Nausea and vomiting & Amenorrhoea & Abnormal menstrual bleeding \\
\hline & Mastalgia & Weight gain & Pelvic infection \\
\hline & Menstrual abnormality & & \\
\hline & Menorrhagia & & \\
\hline \multirow{2}{*}{ Complication } & Missed pill & \multirow{2}{*}{ Return of fertility is late } & Spontaneous expulsion \\
\hline & Nausea & & Intermenstrual bleeding \\
\hline \multirow{3}{*}{ Discontinuation } & Missed pills & \multirow[b]{2}{*}{ Nill } & Pain in abdomen \\
\hline & Non compliance & & Intermenstrual bleeding \\
\hline & 3 monthly & & Missing tnread \\
\hline Hospital visits & 3 monthly & 3 monthly & 6 monthly \\
\hline \multirow{3}{*}{ Time of starting } & After menses & After menses & After menses \\
\hline & & After delivery & After delivery \\
\hline & & After medical MTP & After medical MTP \\
\hline \multirow{5}{*}{ Contraindication } & $\mathrm{BMI}>30 \mathrm{Kg} / \mathrm{m}^{2}$ & Depression & Pelvic infections \\
\hline & Hypertension, & Inj site reaction & Uterine cavity distortion \\
\hline & Diabetes & & Within 6 weeks of LSCS \\
\hline & Circulatory diseases & & \\
\hline & Liver diseases & & \\
\hline \multirow{3}{*}{ Follow up } & \multirow{3}{*}{ Every three monthly } & \multirow{3}{*}{ Every three months } & After first menses \\
\hline & & & 6 monthly for 1 year \\
\hline & & & Then yearly \\
\hline
\end{tabular}

\section{METHODS}

This was a prospective observational study carried out in the Department of Obstetric and Gynaecology at Smt. Kashibai Navale Medical College and General Hospital, Pune from April 2020 to Dec 2020. Women coming to the
OPD for contraceptive advice after medical termination of pregnancy and patients desiring postpartum contraception were included in the study. The three commonly adviced methods of contraception, oral contraceptive pills, Inj DMPA (Depo Provera) and CuT 380A were studied for their side effects, cost effectiveness, availability, 
acceptance and number of hospital visits required. During the 9 months of study period, our hospital was visited by 600 females with unwanted pregnancies and 480 deliveries had took place at our hospital. Total of which made the target of 1080 .

Out of this only 800 females were willing to use some contraception to avoid further pregnancy post-delivery and post MTP .Patient information sheet and consent of the patients to participate in the study was collected and confidentiality was maintained. Patients' data was collected from the MTP register, labour room register, OT register and Copper $\mathrm{T}$ register after taking approval from the Institutional Ethical Committee. Out of 800 patients enrolled in the study 200 lost to follow up. The information collected from the 600 patients were shown in tables, bar graphs and percentage was calculated.

\section{RESULTS}

In this study $76.5 \%$ patients (n-459) accepted Inj DMPA as a method of contraception as compared to $10 \%$ used $\mathrm{Cu}$ $\mathrm{T}$ and $13 \%$ were willing to use OC pills as a method of contraception. Amongst OC pill user $87.5 \%$ patients (n70) were post MTP while $12.5 \%$ patients (n-10) were postdelivery but not breast feeding due to some reason (Table 2).

Table 2: Number of patients using different methods.

\begin{tabular}{|lllll|}
\hline Contraception & Cu T & DMPA & OC pills & Total \\
\hline Post MTP & 35 & 135 & 70 & 240 \\
\hline Post delivery & 26 & 324 & 10 & 360 \\
\hline Total & 61 & 459 & 80 & 600 \\
\hline
\end{tabular}

Amongst $\mathrm{Cu}$ T user (n-61), 63\% patients complaint of pain during periods and $28 \%$ had heavy periods. Around $16 \%$ of CuT user had visited the hospital with excess discharge $\mathrm{P} / \mathrm{V}$ vagina and amongst them $14 \%$ had undergone CuT removal within 9 months. Expulsion rate of $\mathrm{CuT}$ was found around $6 \%$ which was mainly in the cases of post placental CuT insertion (Figure 1).

Inj DMPA was most preferred method (n-459) in this study. Amongst DMPA user irregular P/V spotting was seen in $48 \%$ (Figure 2) but did not necessitate use of sanitary pads and it was not troublesome to the patients. Around 31\% DMPA user had complaints of weight gain as compared to $62 \%$ OC pill users and 20\% DMPA user had mood swings as compared to35\% OC pill users (Figure 3).

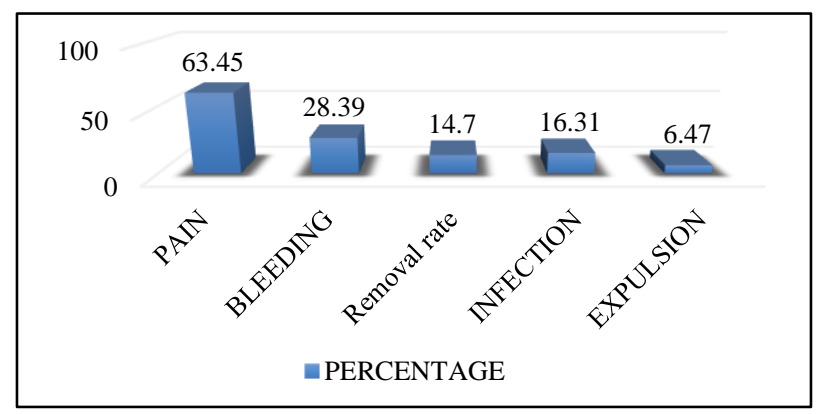

Figure 1: Common Side effects of CuT 380A.

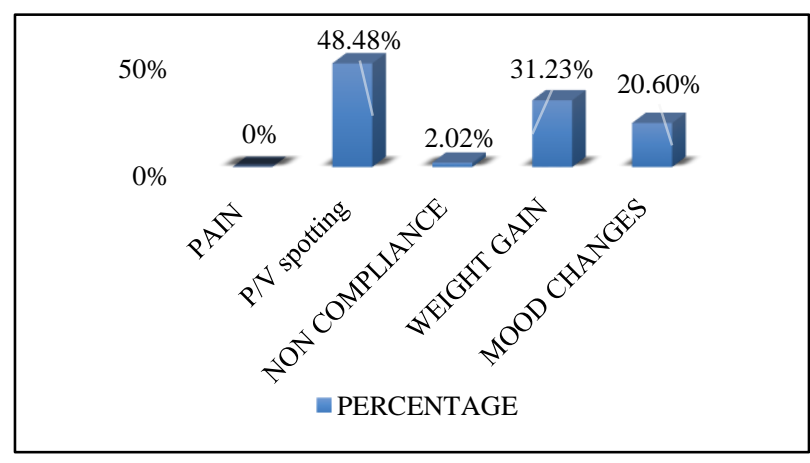

Figure 2: Side effects of Inj DMPA.

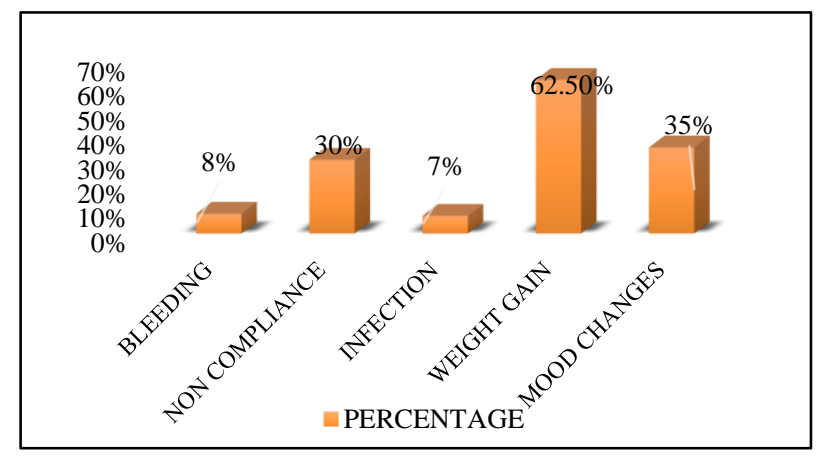

Figure 3: Side effects of $\mathrm{OC}$ pills.

In this COVID pandemic most important factor to be taken into consideration was cost effectiveness, accessibility and number of hospital visits. Although all the 3 methods were affordable for the patients but most of the DMPA user had only 1-2 visits to the hospital (Figure 4).

Table 3: Comparison of cost effectiveness and accessibility of 3 methods.

\begin{tabular}{|ll|ll|}
\hline Comparison & Cut 380 A & DMPA & OC PILLS \\
\hline Cost effective & $\begin{array}{l}\text { Free of cost at our hospital SKNMC } \\
\text { Gh }\end{array}$ & $\begin{array}{l}\text { 150-200 rupees. } \\
\text { (Available in form of Antara, } \\
\text { free of cost) }\end{array}$ & Free of cost Mala N \\
\hline \multirow{2}{*}{ Accessibility } & Need to visit tertiary care centre. & $\begin{array}{l}\text { Can be taken at local hospital } \\
\text { every three monthly }\end{array}$ & $\begin{array}{l}\text { Available over the counter } \\
\text { without prescription. }\end{array}$ \\
\cline { 2 - 3 } & Expert required for insertion & Advice required for initiation \\
\hline
\end{tabular}




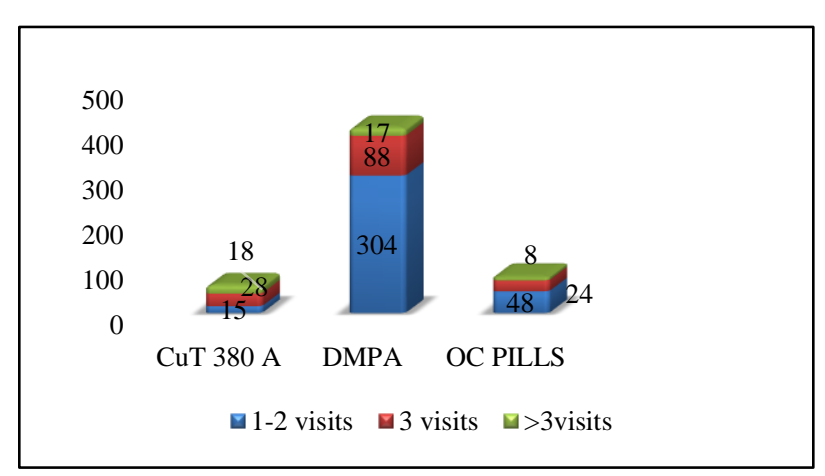

Figure 4: Comparison of hospital visits.

\section{DISCUSSION}

Contraception is one of the most important topic to be discussed in the times of COVID and the things that should be considered is the number of visits patient has to come to the hospital for advice, initiation of the contraception and for the follow up. In this period of strict home quarantine when there is minimal access to the hospital, it is need of the hour to use a contraception which is easily available, cost effective, with lesser side effects and most important with less hospital visits.

In this study all the three contraception that we considered were available free of cost at any tertiary care centre. With $\mathrm{CuT}$ it was observed that most of the patients had fear about the device being inserted into the womb, and had apprehension of its side effects, and showed unwillingness for being unable to come for the follow up. Similarly with the OC pills patient showed inconvenience for its daily oral intake and it was not a method of choice after delivery because of its effect on breast feeding. Most of the patients showed faith in the injectable contraceptive. The majority of women had lactational amenorrhoea which masks the side effect of DMPA. Inj DMPA does not have side effects of estrogen and can be effectively given in lactating women. ${ }^{6}$ Also return of fertility is delayed by few months in DMPA users so it can be the method of choice in this pandemic days for the couples who wants birth control inspite of proximity.

Sayana ${ }^{\circledR}$ Press (medroxy progesterone) is the first injectable contraceptive in the UK available for administration via self-injection. ${ }^{7,8}$ This new method of administration is also approved or pending local approval in additional European Union (EU) markets (Austria, Belgium, Hungary, Ireland, Netherlands). Efforts are being made to bring this to more countries across the globe, with focus on the developing world, where there is high demand for injectable contraceptives. ${ }^{9}$ Sayana ${ }^{\circledR}$ Press is not yet approved for self- injection outside European Union. ${ }^{10}$

\section{Limitations}

This study shows the data from only one centre and has a limited sample size over the given period. To make any inference we need to perform multicentric study with more number of patients over a longer duration of period.

\section{CONCLUSION}

There are different types of contraception, but not all types are appropriate for all situation. This study concludes that most suitable method of contraception during this COVID 19 pandemic is injectable DMPA. It is effective, with minimal side effects and requires less number of hospital visits. It can emerge as the most accepted method of contraception globally, if self-injection gets approval worldwide. Hence injectable DMPA should be made available as a first line method to all those who wishes to opt for reversible method of contraception.

Funding: No funding sources

Conflict of interest: None declared

Ethical approval: The study was approved by the Institutional Ethics Committee

\section{REFERENCES}

1. Bearak J, Popinchalk A, Alkema L, Sedgh G. Global, regional, and subregional trends in unintended pregnancy and its outcomes from 1990 to 2014: estimates from a Bayesian hierarchical model. Lancet Glob Health. 2018;6(4):380-9.

2. World Bank. Trends in Maternal Mortality 2000 to 2017: Estimates by WHO, UNICEF, UNFPA, World Bank Group and the United Nations Population Division. Available at http:// documents. World bank. org/ curated/ en/ 793971568908763231/Trends-inmaternal-mortality-2000- to- 2017- Estimates- byWHO- UNICEF-UNFPA- World -Bank -Group and- the -United-Nations-Population-Division. Accessed at 1 April 2020.

3. Urrutia PR, Polis CB, Jensen ET, Greene ME, Kennedy E, Stanford JB. Effectiveness of fertility awareness-based methods for pregnancy prevention: a systematic review. Contraception. 2018;132(3):591604.

4. Ali M, Bahamondes L, Landoulsi BS. Extended effectiveness of the etonogestrel-releasing contraceptive implant and the $20 \mu \mathrm{g}$ Levonorgestrelreleasing intrauterine system for 2 years beyond U.S. Food and Drug Administration product labeling. Glob Health Sci Pract. 2017;5(4):534-9.

5. Kennedy CE, Yeh PT, Gaffield ML, Brady M, Narasimhan M. Self-administration of injectable contraception: a systematic review and meta-analysis. BMJ Glob Health. 2019;4(2):e001350.

6. Westoff C. Depot medroxyprogesterone acetate injection: a highly effective contraception with proven long term safety. Contraception. 2011;68(2):75-87.

7. National Health Service. The Contraceptive Injection. Available at http:// www. nhs. uk/ conditions/contraception-guide/pages/contraceptiveinjection.aspx. Accessed on 8 September 2015. 
8. Electronic Medicines Compendium. Noristerat SPC. Available at http:// www. medicines. org. uk/ emc/medicine/1835. Accessed on 8 September 2015.

9. FP 2020 Progress Report: 2013-2014. Figures 4.14, AX. 12 and AX. 12. Available at http://progress.familyplanning2020.org/downloads. Accessed on 27 July 2015.
10. FP 2020 Progress Report: 2013-2014. Figures 4.12, AX. 4 and AX. 18. Available at http://progress.familyplanning2020.org/downloads. Accessed on 27 July 2015.

Cite this article as: Patokar MS, Shirsath AS, Shinde SR, Darawade SP. A study of different contraceptive methods: need of an hour during COVID 19 pandemic. Int J Reprod Contracept Obstet Gynecol 2021;10:2749-53. 